\title{
LIBERTAS QUE SERÁS ENFERMAGEM
}

\author{
FREE THEN THOU SHALL BE NURSING \\ LIBERTAD QUE SERÁS ENFERMERÍA
}

\begin{abstract}
Mary Anne Fontenele Martins ${ }^{1}$
Débora Rodrigues Guerra ${ }^{2}$ Maria Vilani Cavalcante Guedes ${ }^{3}$
\end{abstract}

\begin{abstract}
RESUMO: O título deste ensaio nos faz lembrar a Inconfidência Mineira, que teve como líder José Joaquim da Silva Xavier, o Tiradentes, sendo um movimento que ansiava por liberdade, assim como a enfermagem que, ao longo dos anos, vem construindo sua história e caminhando em busca de sua autonomia. A presente pesquisa tem como objetivo investigar os caminhos percorridos pela enfermagem, enquanto ciência na busca de sua autonomia, e refletir sobre a atuação do enfermeiro enquanto profissional criativo e autônomo. Estudo respaldado no materialismo histórico e dialético, realizado no periodo de maio a agosto de 1997 com enfermeiras do Estado do Ceará, que estão envolvidas com o processo histórico da profissão. Os resultados deram origem a uma categoria central, prática profissional e outras três: autonomia, criatividade e disposição para enfrentar desafios, que favoreceram uma melhor compreensão dos caminhos já trilhados pela enfermagem, além de nos permitir entender que o enfermeiro pode ser autônomo e livre.
\end{abstract}

PALAVRAS-CHAVE: Enfermagem - Liberdade - Autonomia - Prática profissional

\begin{abstract}
The title of this effort has reminded us of the Inconfidência Mineira, that had José Joaquim da Silva Xavier, the Tiradentes as its leader. It was a movement that longed for freedom, like nursing that, along the years, has been building its history and has been walking in search of its autonomy. This study has aims at investigating the ways nursing has gone through, while a science, it searches for its autonomy and mediates about nurse's performance while an autonomous and creative professional. This study had the historical materialism as support. It was accomplished from May to August, 1997 with nurses from Ceará that were involved with the profession historical process. The results originated a central category, professional practice, and the other three ones: autonomy, creativity and disposition to face challenges, that favour a better comprehension about the paths nursing tracked, besides permitting us to understand that the nurse can be autonomous and free.
\end{abstract}

KEYWORDS: Nursing - Freedom - Autonomy - Professional Practice

\footnotetext{
${ }^{1}$ Acadêmica de enfermagem da Universidade Estadual do Ceará e Bolsista PET/ CAPES

${ }^{2}$ Acadêmica de enfermagem da Universidade Estadual do Ceará e Bolsista PET/ CAPES

${ }^{3}$ Enfermeira, Mestra em Educação, Docente Adjunta do Departamento de Enfermagem da Universidade Estadual do Ceará e Tutora do PET/CAPES.
} 
RESUMEN: EI título de este ensayo nos hace recordar la "Inconfidência Mineira", que tuvo como líder José Joaquim da Silva Xavier, o Tiradentes, siendo un movimiento que ansiava por libertad, asi como la enfermeria que, a lo largo de los años, viene contruyendo su historia y caminando en busca de su autonomía. La presente pesquisa tiene como objetivo investigar los caminos recorridos por la enfermeria, encuanto ciencia en la búsqueda de su autonomía, y reflexionar sobre la actuación del enfermero encuanto profesional creativo y autónomo. Estudio respaldado en el materialismo histórico y dialectico, realizado en el periodo de mayo a agosto de 1997 con enfermeras del Estado de Ceará, que están envueltas con el proceso histórico de la profesión. Los resultados dieron origen a una categoría central, práctica profesional y otras tres: autonomía, creatividade y disposición para enfrentar desafios, que permitieron una mejor comprensión de los caminos ya recorridos por la enfermería, además de permitirnos entender que el enfermero puede ser autónomo y libre.

PALABRAS CLAVE: Enfermería - Libertad - Autonomía - Práctica profesional

\section{INTRODUÇÃO}

A enfermagem, ao longo destes anos, vem construindo a sua história e contribuindo de maneira satisfatória para o engrandecimento da humanidade. Ao retomarmos o passado desta ciência, observaremos uma luta constante em busca de autonomia e reconhecimento pela sociedade, chegando esta discussão aos dias atuais. Entendemos, aqui, que esta busca näo precisa ser necessariamente através de grandes atos, porém construída no dia-a-dia do profissional, nas atividades, nas atitudes e decisões tomadas no seu exercício de cuidar.

Consideramos que o enfermeiro é um profissional autônomo, competente, independente e detentor de conhecimentos e práticas cientificas. Contudo, algumas pessoas não reconhecem isto, consideram-no como auxiliar de médico, submisso e que cumpre apenas tarefas e ordens prescritas. $\mathrm{E}$ algumas destas pessoas são médicos, diretores de hospitais, e até mesmo enfermeiros.

Waldow (1990) considera liberdade como "o objetivo de desnudar e possibilitar o repensar, o re-fazer, o re-criar. Liberação no sentido de metamorfose para o derradeiro vôo na direção da liberdade, da transformação(...). É o processo de busca de si mesmo e de nossas ações de forma responsável e madura." Neste sentido, liberdade assume uma dimensão transcultural, onde a enfermagem conquista e apropria-se do próprio existir.

Observamos um campo enorme de atuação para o enfermeiro, seja dentro de um hospital ou em uma faculdade, unidades de saúde pública, e em outros locais de trabalho. Só depende da categoria mostrar seu potencial e esclarecer a toda sociedade quem é o enfermeiro e o que este faz. É através da competência do profissional no seu cotidiano que aos poucos todos podem compreender melhor o verdadeiro papel desta profissão, respeitando-a e reconhecendo-a como tal. 
Mas é preciso que os próprios profissionais tomem consciência das atribuições especificas da enfermagem, mostrem que possuem um fazer diferenciado, com compromisso e baseado na relação interdisciplinar com os outros profissionais. Cruz (1996) acredita que "a autonomia continuada em favor de terceiros é um dos requisitos para que se alcance o 'status' da profissão".

A enfermagem vem se organizando em busca de sua plena autonomia, tendo uma participação crescente nas decisões éticas e politicas. Temos uma categoria organizada em entidades de classe lutando pela melhoria, contudo observamos atitudes individuais que tentam melhorar os serviços, a qualidade da assistência de enfermagem, sendo consideradas fatores que contribuem para o processo histórico da enfermagem.

Autores como Lunardi(1995) e Cruz (1996) questionam-se se o enfermeiro tem autonomia no exercício de suas atividades. Deste modo, resolvemos elaborar um estudo sobre esta autonomia, demonstrando que é possivel refletir sobre as ações de enfermagem e o ser enfermeiro, capaz de assumir suas limitações, capacidades e decisões como ser humano no seu verdadeiro existir.

\section{OBJETIVOS}

- Investigar os caminhos percorridos pela enfermagem, enquanto ciência, na busca de sua autonomia;

- Identificar as ações do enfermeiro que contribuem para a construçäo de uma prática autônoma;

- Refletir sobre a atuação do enfermeiro enquanto profissional criativo e autônomo;

- Analisar as atividades inovadoras por parte de enfermeiros, que caracterizam a busca de liberdade.

\section{DA ORIGEM À ATUALIDADE: EM DIREÇÃO À LIBERDADE}

A enfermagem surgiu do trabalho religioso, onde, inicialmente, eram irmãs de caridade que exerciam a tarefa de cuidar dos doentes, miseráveis e mendigos. As atividades se limitavam à higiene e administração de medicamentos. Nesta época, identificamos um momento de grande expansão industrial resultando numa revolução que envolveu toda a humanidade. Antes, o trabalho de cuidar era exercido pelas donas-de-casa, mães, mulheres que detinham 0 conhecimento terapêutico das ervas e que durante a Idade Média foram acusadas de bruxas pela Santa Inquisição. Lima (1994) coloca que

as mulheres enfermeiras sempre existiram, desde tempos imemoriais, circulando de casa em casa, de cidade em cidade, cuidando de outras mulheres, crianças, idosos, deficientes e pobres. Esses cuidados incluiam fazer partos, assistir recém-nascidos, ensinar higiene, fazer curativos e oferecer apoio entre outras atividades. 
O ensino informal era baseado em ênfase nas atividades práticas, sem o conhecimento teórico adequado e sem produção de conhecimentos. Ainda concordando com Lima (1994), os saberes relacionados ao cuidar eram repassados através de gerações, sendo as mulheres consideradas como "sábias" e que poderiam prejudicar os interesses das autoridades.

Temos procurado no contexto histórico subsídios para compreendermos porque a enfermagem se tornou predominantemente feminina. $\mathrm{Na}$ época de sua organização como profissão, a mulher era considerada um ser inferior ao homem, sendo, portanto, submissa a ele, não gozando de liberdade para exercer cidadania, ou trabalhar no mercado, permanecendo numa condição em que seu papel social era determinado pelo seu papel sexual. Pires (1989) acrescenta sobre a sociedade brasileira:
A família ampliada de elite, aristocrata e rural até 1800, e a família nuclear e citadina da sociedade oitocentista eram a base da estrutura de poder na sociedade brasileira, de características predominantemente feudais, sem um estado efetivamente estruturado e dependente da metrópole portuguesa. A família era patriarcal e autoritária; as mulheres $e$ as crianças eram subservientes aos homens privilegiados $e$ dominantes.

No processo de institucionalização da medicina, apenas os homens poderiam aprender o ofício, sendo explícito a relação de poder entre homem e mulher refletido nas duas profissões, considerando a divisão técnica do trabalho e o domínio do saber. Consideramos que um dos fatores explicativos da existência de situações conflitantes na relação enfermagem-medicina seja pelo processo histórico no qual as duas profissões foram envolvidas. "A dominação médicoenfermagem não é só o resultado da dominação homem-mulher, mas a historicidade do papel de exclusão feminina certamente contribui na reprodução das relações de poder de dominação-submissão até hoje presentes no setor saúde" (Loyola, 1987).

Dessa maneira, os trabalhos caritativos foram exercidos pela mulher, não sendo reconhecidos pela sociedade, pois não havia a geração de lucros, e o que mais importava no momento era a movimentação financeira, o capitalismo.
A maior parte do trabalho realizado na sociedade capitalista assume característica de trabalho alienado, ou seja, aquele sobre o qual a maior parte dos trabalhadores, entre eles os da própria enfermagem, não detém sequer o conhecimento da totalidade do processo produtivo, quanto mais o controle da produção ou da riqueza social gerada a partir dela (Fonseca, 1995).

Assim, a enfermagem moderna começa a se organizar como profissão emergente, na Inglaterra, com objetivos de servir à pátria e obedecer às ordens médicas, ficando claro que eram somente mulheres que poderiam exercê-la e mediante a supervisão direta daqueles considerados os detentores do saber, os médicos. 
No Brasil, não houve grande diferença, pois o modelo da Inglaterra fora implantado nas incipientes escolas de enfermagem. Ressaltamos que a idéia de termos uma profissão submissa à medicina em nosso país, que apenas executasse as prescrições, partiu justamente da classe médica que estava ao lado do governo e detinha o conhecimento sobre a saúde.

Germano (1993) nos conta que

essa hierarquia vigente no hospital com total poder ao médico, segundo Focault(1979:110), "se manifesta no [próprio] ritual da visita, desfile quase religioso em que o médico, na frente, vai ao leito de cada doente seguido de toda a hierarquia do hospital: assistentes, alunos, enfermeiras etc." Essa codificação ritual da visita, que marca $o$ advento do poder médico, é encontrada nos regulamentos de hospitais do século XVII, em que se diz onde cada pessoa deve estar colocada, que o médico deve ser anunciado por uma sineta, que a enfermeira deve estar na porta com um caderno nas mãos e deve acompanhar o médico quando ele entrar.

A própria história tomou seu curso, de modo que a mulher conquistou seus direitos cívicos, a sua liberdade de expressão, e entrou no mercado de trabalho, competindo com o sexo oposto, incluindo a enfermagem neste contexto e que ainda não conquistou a sua completa autonomia, mantendo-se ainda submissa a categoria médica. Ela está organizada como profissão institucionalizada e reconhecida por lei, dona do seu saber e sua prática definidos na teoria. Porém, a sociedade ainda não reconhece a enfermeira como uma profissional da saúde que é capaz, competente, independentemente e detentora de uma prática. Muitos a consideram como auxiliar de médico, apesar do nível superior, que cumpre apenas as ordens prescritas.

Antunes (1995) ressalta que nas fontes remotas da história da humanidade e das mulheres poderemos encontrar pistas que identifiquem a busca da autonomia: "um saber próprio, coletivo, relevante, capaz de restituir à enfermagem o papel social e o poder exclusivo de prestar cuidados integrais à vida, e não mais só de tratadoras de doenças subordinadas ao conhecimento de outra ciência e de outras profissões".

Estamos a um passo do século $\mathrm{XXI}$, onde a modernidade vai chegando a todas as classes e a enfermagem promete ser uma profissão emergente neste início de século. E são iniciativas isoladas de alguns que devemos tomar como exemplos para outros enfermeiros, servindo de ações norteadoras do exercício profissional, coletivo, capaz e plenamente autônomo, reconhecido por todos e pela sociedade.

\section{METODOLOGIA}

A abordagem metodológica deste estudo perpassa pelo materialismo histórico e dialético, visto que partimos do princípio da historicidade, pois este 
garante um modo no qual o pesquisador é capaz de investigar o desenvolvimento histórico do objeto estudado. Acreditamos que, analisando a evolução da enfermagem como ciência, podemos identificar pontos que corroboram para interpretar a atual realidade vivida por esta profissão.

Utilizamos esta abordagem porque Triviños (1987) esclarece que o materialismo preconiza que os vínculos estabelecidos entre os homens podem "ser de relações mútuas de cooperação, de submissão ou de um tipo de relação que signifique transição entre as formas assinaladas".

É importante para o pesquisador conhecer as relações situadas no meio e quais os indicadores que acrescentam para a existência de determinada situação. Assim, as relações que permeiam a prática do enfermeiro são evidenciadas por indicadores sociais, politicos, históricos e econômicos da realidade que envolve a sociedade.

Guedes (1990) afirma que a concepção de ciência dotada pelo materialismo é adequada "para identificar e compreender os elementos necessários ao desvendamento da realidade da prática, entendida esta em uma relação com as demais práticas sociais desenvolvidas em uma sociedade de classes". Em suma, num contexto real, no qual predomina a divisão de classes e o modo de produção capitalista, pretendemos identificar a postura que o enfermeiro assume enquanto ser responsável pela transformação social de sua prática.

Adotamos, para melhor compreensäo do objeto deste estudo, a metodologia qualitativa. Escolhemos enfermeiras do Estado do Ceará, que estão envolvidas com o processo histórico da profissão, e que, ao longo de sua trajetória profissional, puderam contribuir para a conscientização de que a enfermagem é sujeito de sua evolução no contexto político e social.

A coleta de dados foi feita através de uma entrevista, que possuia uma pergunta norteadora, acrescentando outras perguntas que complementariam a primeira. Após a transcrição das entrevistas, analisando os depoimentos e utilizando a terminologia adotada pelo materialismo, percebemos uma categoria central, denominada por prática profissional e outras três categorias, assim colocadas: autonomia, criatividade e disposição para enfrentar desafios.

\section{ARTICULANDO OS RESULTADOS}

Como categoria central, a prática profissional do enfermeiro é entendida como o conjunto de ações desenvolvidas por este enquanto sujeito consciente e detentor de um saber. Angelo (1996) aponta que a prática de enfermagem não é uma prática apenas porque enfermeiros a realizam, mas sim porque é baseada em conhecimentos de enfermagem. E é justamente o que causa uma profunda diferença, "não apenas na própria profissão mas na natureza das interações profissionais, nas relações enfermeiro-paciente e na qualidade de vida das pessoas cuidadas". 
Diante disso, ressaltamos a importância da tomada de consciência do profissional enfermeiro, sendo capaz de desenvolver uma atividade específica, relevante $\mathrm{e}$ independente, sem reproduzir o conhecimento médico e sem executar tarefas, de modo que possa demonstrar a sua competência e liberdade quando nas decisões, resguardando sempre a qualidade da assistência prestada à sua clientela e seus principios éticos e morais.

Germano (1995) cita Vásquez que afirma que, para Marx,

o homem real é, em unidade indissolúvel, um ser espiritual e sensivel, natural e propriamente humano, teórico e prático, objetivo e subjetivo. O homem é antes de tudo, praxis: isto é, define-se como ser produtor, transformador, criador; mediante o seu trabalho, transforma a natureza externa, nela se plasma e, ao mesmo tempo, cria um mundo à sua medida, isto é, à medida de sua natureza humana..

Dadas estas características do homem, entendemos que o enfermeiro é sujeito de sua realidade, desde que ele tenha consciência critica da sua atuação no contexto da saúde e da ordem vigente, como as políticas da saúde, para que ele não apenas seja um simples fantoche manipulado pelos detentores do poder dentro das decisões políticas que viabilizam a prestação de serviços ao povo.

\section{Afinal, o que é autonomia?}

Nesta categoria, de acordo com Batey e Lewis citados por Cruz (1996), a autonomia "é basicamente a liberdade para fazer escolhas, tomar decisões ou selecionar um curso de ação sem controle externo", ou seja, o enfermeiro deve ter a liberdade de decidir qual o melhor plano de cuidados direcionado ao paciente, sem depender da opinião de qualquer outro profissional.

Uma das entrevistadas refere que a autonomia da enfermagem está diretamente relacionada ao aspecto histórico:
" $A$ enfermagem é uma profissão nova, porque na história, as coisas que têm 50 anos são consideradas novas. Nós não podemos nos comparar com profissões que já são tradicionais como a medicina e o direito. Eu acredito que a autonomia é construída, é feita pelo profissional no seu exercício do dia-a-dia. E a enfermagem está a cada dia exercendo uma prática mais autônoma."

Analisando fatos históricos, entendemos que a categoria médica exerceu poder de dominação em relação à enfermagem, sendo esta uma profissão subsidiária da medicina, como afirmou esta depoente. Contudo, acreditamos que, ao longo dos anos, a enfermagem vem tentando construir um saber e uma prática diferenciados, adquirindo cada vez mais autonomia através de pessoas que acreditaram em seu potencial e trilharam com suas atitudes um caminho diferente para a profissão. 
Compreendemos que a relação médico-enfermeira não deve ser de superioridade ou inferioridade, mas $\operatorname{sim}$ de igualdade, já que ambos desenvolvem suas atividades com um propósito maior: o bem-estar do individuo, da familia e da comunidade. Assim concordamos com uma das entrevistadas que afirmou:

"Se nós trabalhamos com um médico, ao lado dele, temos que entender que é um trabalho de iguais. Cada um desempenha suas atividades de uma forma autônoma"

Observamos que o profissional pode ser interdependente, mas não independente, de modo que haja um trabalho conjunto, no qual diversos profissionais desempenham o seu papel cooperando uns com os outros, exercendo cada um a sua autonomia.

Para o exercício da autonomia, as entrevistadas consideram a competência como caracteristica essencial, como os depoimentos a seguir:

"A pessoa competente é aquela que tem conhecimento suficiente de tudo que pode, mas este conhecimento deve estar associado a boa qualidade de relacionamento interpessoal com toda a equipe de saúde, pois esta equipe é uma equipe de iguais, que deve estar integrada para o trabalho andar bem."

"O profissional competente é aquele que tem conhecimento teórico, não só habilidade manual, mas conhecimento científico. De modo que dá para ele participar da equipe de saúde no mesmo nível, pois assim tem condições de argumentar, de conversar, de expor o que está pensando"

Diante destas opiniōes, percebemos que as enfermeiras deste grupo atrelam a competência à detenção de conhecimentos cientificos para embasar as discussões e ações do seu fazer profissional. Além disso, uma delas refere-se ao bom relacionamento interpessoal como caracteristica da competência. Consideramos que seja essencial, para o desenvolvimento do trabalho de uma equipe de qualidade, a integração entre seus componentes, pois, deste modo, cada um pode exercer sua autonomia, interagindo e trabalhando a interdisciplinaridade.

Outro aspecto relacionado com a autonomia é a questão política, citada no decorrer das entrevistas:

"Uma profissão autônoma é quando você tem consciência política, tem competência para exercer a sua atividade(...); é quando você reconhece os seus direitos e compreende os direitos do outro(...). Você nunca faz nada só. A autonomia é construída pela gente. Não é pelo outro profissional; profissional nenhum me dá autonomia. Esta é uma busca" 
"A autonomia está relacionada à consciência política, desde os seus direitos como simples cidadão. Não é só a sua parte como profissional ali dentro do seu serviço, mas é também você ter uma visão global de tudo que está ao seu redor"

Estes depoimentos expressam a necessidade de uma maior conscientização política por parte da categoria da enfermagem, sendo uma pauta discutida quando se fala em autonomia. Melo (1995) acrescenta que

para a maioria dos enfermeiros não existe sequer a discussão do significado político que é o portador de todo conhecimento, ao conferir a quem detem a capacidade - e portanto, o poder - de transformar a natureza, e nem dos processos e métodos usados nesta transformação ainda é incipiente enquanto consciência política.

Sentimos, então, a necessidade de uma formação nas escolas de enfermagem baseada no processo de conscientização política para que os futuros enfermeiros tenham a visão de que a enfermagem pode e deve se constituir como profissão autônoma e capaz de transformar a sua realidade.

\section{A criatividade nos caminhos da enfermagem}

A criatividade é uma caracteristica do ser humano essencial à evolução da humanidade. Se não fosse pela ousadia de alguns, pela curiosidade de outros, não haveriamos chegado à época moderna em que vivemos rodeados de novas criações.

Ser criativo não significa apenas ser um gênio artístico, mas sim ter atitudes criativas nas quais existe a mudança, a transformação daquilo que era antigo e ultrapassado, no que é inovador. A criatividade surge a partir do momento em que o sujeito procura mudar a sua rotina; a criação é para o criador algo diferente e que lhe traz prazer. Dada esta definição, vejamos, agora, o seguinte depoimento:

"Sou um tanto criativa. Realmente eu gosto, inclusive, de ver o que tem para fazer. Para desenvolver, se for para engrandecer a enfermagem, eu procuro construir o que eu posso. Nunca destruir e valorizar sempre."

Desta maneira, é possível prever mudanças no campo de trabalho da enfermeira, desde que ela utilize um simples instrumento básico: a criatividade. Ou seja, se desejamos uma profissão autônoma, livre do comando de outros, trabalhando a interdisciplinaridade, precisamos criar meios diferentes dos que já existem para transformar a nossa prática e sermos reconhecidos pela sociedade.

$\mathrm{Na}$ sociedade capitalista, ao proletariado é oferecida uma carga de trabalho constante, de modo que todas as suas energias são canalizadas para o trabalho manual. Assim, este caráter repressivo impede o pensar e agir com criatividade desenvolvendo uma prática de trabalho essencialmente intuitiva. Da mesma 
forma, o enfermeiro, sendo um trabalhador assalariado, vivendo numa relação empregado-patrão, permanece num sistema em que tudo é feito em nome do lucro. As exigências, a sobrecarga de trabalho, fazem com que alguns membros da categoria se acomodem, 'cruzem os braços' diante das novas propostas de mudanças que surgem, como, por exemplo, o diagnóstico de enfermagem. Referente ao assunto, observemos este depoimento:

"Nós estamos querendo melhorar a prescrição, querendo treinar, querendo tirar aqueles profissionais que só funcionam no empurrão; estamos querendo mudar a postura do enfermeiro frente aos outros profissionais."

São atitudes como estas que são consideradas criativas, inovadoras. Gerar, formar, dar existência, tirar do nada, dar princípios, produzir, inventar, imaginar, estabelecer, cultivar são palavras que fazem parte do ato de criar.

\section{Desafios: é possivel enfrentá-los?}

Definimos essa categoria como sendo a capacidade que as entrevistadas demonstraram em buscar soluções e desafiar as pessoas e/ou situações que se apresentam como desafios, e que determinam a utilizaçăo da criatividade e a representação de uma prática profissional autônoma.

Os depoimentos abaixo retratam isto:

"Há alguns anos atrás, eu fui chamada para assumir uma chefia na Secretaria de Saúde do Estado, que até então, só era exercida por médicos. Alguns até 'chiaram' de início, mas eu me esmerei em fazer o melhor que eu pude. $O$ que estava bem acima de minhas forças. $E$, realmente, foi uma oportunidade muito grande de eu me impor como profissional numa atividade de nível superior, que poderia ser ocupada por qualquer pessoa da área.(...). Eu nunca fui procurar cargo nenhum, nunca pedi e nunca procurei, sempre fui convidada. Assim, eu acho que valeu todo esforço, toda a minha vontade de progredir."

"Se você me der um problema para eu resolver e acham que não tem mais solução, eu vou encontrar um 'jeitinho' de dar o resultado final. Estou sempre fazendo as coisas de um jeito ou de outro, mas nunca deixo sem solução. Assim, eu sempre trabalhei em coisas que, geralmente, as pessoas acham dificeis: trabalhei no serviço X e tudo que foi feito lá, foi com muita dificuldade, mostrando o porque de cada coisa, mostrando que sabia; as pessoas no começo, ficaram duvidando que a gente podia fazer. Havia pessoas que queriam elevar o serviço e outras que só queriam destrui-lo, mas trabalhei muito e provei para muitos que não acreditavam na enfermeira e hoje eles sabem me respeitar. (...) Acho que isso é importante para o desenvolvimento da profissão". 
Através destes depoimentos, podemos entender que os desafios são encontrados comumente no decorrer da vida. Em se tratando da enfermagem, as dificuldades são muitas, principalmente no que diz respeito aos preconceitos que alguns profissionais têm em relação ao enfermeiro; muitas vezes duvidam da sua capacidade e não o consideram como detentor de conhecimentos.

De acordo com Oliveira citado por Lunardi (1995), "a enfermeira, no seu fazer, pode ter sua autonomia profissional ameaçada, o que comprometeria sua ação técnico-científica-moral, pondo em risco a finalidade da profissão, entendida como dar respostas às necessidades sociais." Assim, entendemos que ela precisa estar convicta da realização das suas atitudes sem permitir que sua prática profissional autônoma seja ameaçada.

\section{UMA REFLEXÄO...}

Como poderemos concluir este trabalho se a enfermagem encontra-se numa busca constante de autonomia? Poderemos, então, entender que este estudo vem somar-se às inúmeras discussões sobre esta temática.

$\mathrm{Na}$ verdade, consideramos que este possa provar que existem instrumentos, como a criatividade, e características, como a disposição para enfrentar desafios, que contribuem para o desenvolvimento de uma prática profissional autônoma.

Esta autonomia é construida no cotidiano dos profissionais que visam a transformação das ações de enfermagem em atitudes independentes de outras profissões e voltadas, principalmente, para lidar com o ser humano. Se hoje em dia poucas são as enfermeiras que percebem estas possibilidades de mudança, devemos, então, tomar como ponto de referencia os profissionais que têm consciência de que é possivel tornar realidade algo que é novo, inédito, ao invés de apenas sonhar, criticar ou simplesmente acomodar-se com a situação.

Elaborar um estudo que discute a questão da liberdade não é tarefa fácil, contudo, há recompensa na medida em que favorece o conhecimento dos caminhos que já foram trilhados pela enfermagem, fornecendo subsídios para compreendermos o presente e construirmos um futuro promissor da profissão, de modo que os enfermeiros pratiquem efetivamente o exercício da autonomia na sua atuação, independente de ser na saúde individual, familiar ou coletiva.

Propomos, assim, que as mudanças ocorram a partir das escolas e cursos de enfermagem, de maneira que os futuros enfermeiros possam entrar no mercado de trabalho com um conceito melhor elaborado acerca da autonomia profissional e uma prática mais consciente a serviço da população menos favorecida, que possui como única alternativa o serviço público de saúde. Para isso, estes profissionais precisam compreender que, sendo livres, provavelmente cada um se tornará um agente de mudança da situação que aí está. 


\section{REFERÊNCIAS BIBLIOGRÁFICAS}

1. ANGELO, M.. Enfermagem: um passaporte para a primeira fila. R. EsC. Enferm. da USP, v. 30, n. 2, p.181-186, Ago., 1996.

2. ANTUNES, M. J. M.. Enfermagem como espaço de inserção de trabalhadores não qualificados. CONGRESSO BRASILEIRO DE ENFERMAGEM, 47, 1995,Goiânia. Anais... Goiânia:ABEn,1995.p.3751.

3. CRUZ, D. de A. L. M. da. . Contribuições do diagnóstico de enfermagem para a autonomia da enfermeira. SIMPÓSIO NACIONAL SOBRE DIAGNÓSTICO DE ENFERMAGEM, 3, 1996, Fortaleza. Conferência... Fortaleza: ABEn, $1996.10 \mathrm{p}$.

4. FONSECA, R. M. G. S. da.. Mulher, trabalho e enfermagem: o nexo coesivo. CONGRESSO BRASILEIRO DE ENFERMAGEM, 47, 1995,Goiânia. Anais... Goiânia: ABEn, 1995.p.79-90.

5. GERMANO, R.M.. A ética e o ensino de ética na enfermagem do Brasil. São Paulo: Cortez, 1993,141p.

6. GUEDES, M. V. C.. Prática técnica, educativa e social do enfermeiro em uma instituição hospitalar: estudo de caso. Dissertação (Mestrado em Educação) Fortaleza, Universidade Federal do Ceará. $1990,175 \mathrm{p}$.

7. LIMA, M. J. de. . O que é enfermagem. São Paulo: 2. ed. Brasiliense, 1994.102p

8. LOYOLA, C. M. D.. Os dóce(i)s corpos do hospital. Rio de Janeiro: UFRJ, 1987, 138p.

9. LUNARDI, V. L.. Uma crítica da moral da obediência para a busca de uma moral autônoma da enfermeira. Texto e Contexto Enferm.; Florianópolis, v. 4, n. 2, p. 73-92, jul./dez., 1995.

10. MELO, C. M. M.. As interfaces do poder no setor saúde e no trabalho de enfermagem: o jardim de caminhos que se bifurcam. CONGRESSO BRASILEIRO DE ENFERMAGEM, 47, 1995,Goiânia. Livro Síntese... Goiânia: ABEn, 1995. p. 71-72.

11. PIRES, D.. Hegemonia médica na saúde e a enfermagem. São Paulo: Cortez, $1989.154 \mathrm{p}$.

12. TRIVIÑOS, A. N. S.. Três enfoques na pesquisa em ciências sociais: o positivismo, a fenomenologia e o marxismo. In: pesquisa em ciências sociais. São Paulo: Atlas, 1987. p. 49-63.

13. WALDOW, V. R.. O Ensino de enfermagem numa dimensão feminista e existencialista: uma reflexão crítica para a liberação. Revista Gaúcha de Enferm., Porto Alegre, v. 11, n.2, p.35-40, jul., 1990. 